\title{
PENGARUH PENGGUNAAN APLIKASI WHATSAPP GROUP DAN GOOGLE CLASSROOM TERHADAP MOTIVASI DAN HASIL BELAJAR KOGNITIF SISWA
}

\author{
Fina Aenilah ${ }^{1}$, Yoyon Sutresna ${ }^{2}$, Taupik Sopyan ${ }^{3}$ \\ 1,2,3 Program Studi Pendidikan Biologi, Universitas Galuh, Jl. R. E. Martadinata No.150 , Ciamis, Indonesia \\ email: finaaini26@gmail.com
}

\begin{abstract}
The learning process is usually carried out actively and effectively in schools. Now, due to the COVID-19 pandemic, learning is hampered and not fully implemented. Thus the learning process switches to a distance learning system. During the process of implementing learning, appropriate learning applications are needed to support the learning process correctly and effectively. The applications that are considered suitable are WhatsApp and Google Classroom. The purpose of this study was to determine the effect of using whatsapp and google classroom applications on students' motivation and learning outcomes. The time of the study was carried out in April 2021. The population in this study were students of class XI IPA SMA Negeri 1 Sukadana. The sample used was 21 students of class XI IPA 1. The research design used one group pretest posttest design. In this research, the method used is quasi experimental. The instrument used is a questionnaire consisting of 12 statement items and a question consisting of 20 multiple choice questions. The data obtained were analyzed using a statistical approach with the Wiloxcon test formula for motivation and $z$ test for students' cognitive learning outcomes. The results showed that the use of whatsapp and google classroom applications did not significantly affect students' motivation and cognitive learning outcomes in biology subjects.
\end{abstract}

Keyword : google classroom, learning outcomes, motivation, whatsapp

\begin{abstract}
ABSTRAK
Proses pembelajaran biasanya dilakukan secara aktif dan efektif disekolah. Kini, akibat pandemic covid-19 pembelajaran terhambat dan tidak terlaksana sepenuhnya. Dengan demikian proses pembelajaran beralih ke sistem pembelajaran jarak jauh. Selama proses pelaksanaan pembelajaran, diperlukan aplikasi belajar yang tepat untuk menunjang proses pembelajaran dengan benar dan efektif. Adapun aplikasi yang dirasa cocok adalah whatsapp dan google classroom. Tujuan dari penelitian ini adalah untuk mengetahui pengaruh penggunaan aplikasi whatsapp dan google classroom terhadap motivasi dan hasil belajar siswa. Waktu penelitian dilaksanakan pada bulan April 2021. Populasi pada penelitian ini adalah siswa kelas XI IPA SMA Negeri 1 Sukadana. Sampel yang digunakan adalah 21 orang siswa kelas XI IPA 1. Desain penelitian menggunakan one group pretest posttest desaign. Dalam penelitian ini metode yang digunakan adalah quasy experimental. Instrumen yang digunakan adalah angket yang terdiri atas 12 item pernyataan dan soal yang terdiri 20 item pertanyaan pilihan ganda. Data yang diperoleh dianalisis menggunakan pendekatan statistik dengan rumus uji wiloxcon untuk motivasi dan uji z untuk hasil belajar kognitif siswa. Hasil penelitian menunjukkan bahwa penggunaan aplikasi whatsapp dan google classroom tidak berpengaruh secara signifikan terhadap motivasi dan hasil belajar kognitif siswa pada mata pelajaran biologi.
\end{abstract}

Kata kunci : google classroom, hasil belajar, motivasi, whatsapp

Cara Sitasi : Aenilah, F., Sutresna, Y., \& Sopyan, T. (2021). Pengaruh Penggunaan Aplikasi Whatsapp Group Dan Google Classroom terhadap Motivasi dan Hasil Belajar Kognitif Siswa. J-KIP (Jurnal Keguruan dan IImu Pendidikan), 2(3), 207-212. 


\section{PENDAHULUAN}

Secara nasional pendidikan dijelaskan sebagai usaha yang dilakukan secara sadar dan disusun secara terencana dalam upaya untuk mewujudkan cita-cita dengan menciptakan suasana belajar yang menarik dan menyenangkan, agar peserta didik secara aktif mengembangkan potensi di dalam dirinya, sehingga memiliki kekuatan spiritual, pengendalian diri, kepribadian, kecerdasan, akhlak yang mulia serta keterampilan yang diperlukan baik untuk diri peserta didik itu sendiri maupun untuk masyarakat, bangsa dan negaranya.

Dalam pendidikan dapat diketahui bahwa pada prosesnya tidak terlepas dari proses belajar dan pembelajaran. Menurut Emda (2017) belajar adalah perubahan perilaku yang relatif tetap dan menyatu dalam diri seseorang serta akanterus mencari informasi sehingga mendapatkan pengetahuan baru. Sementara itu, menurut Thobroni (dalam Amalia, 2019) pembelajaran merupakan suatu proses belajar yang berulang-ulang dan menyebabkan adanya perubahan perilaku yang disadari dan cenderung bersifat tetap. Demikian juga Pringgawidagda (dalam Amalia, 2019) menuturkan bahwa pembelajaran adalah suatu perubahan perilaku yang relatif tetap dan merupakan hasil praktik yang diulang-ulang.

Biologi adalah salah satu ilmu yang sangat penting untuk dipelajari bagi kehidupan. Hal ini karena merupakan suatu ilmu pengetahuan alam yang sangat berkaitan erat dengan kehidupan sehari-hari seperti makhluk hidup, lingkungan maupun interaksi yang terjadi antara makhluk hidup dengan lingkunganya.

Dengan kondisi dimana peserta didik yang biasanya melakukan aktivitas belajar dan mendapatkan materi secara utuh dan langsung dari guru serta proses pembelajaran yang aktif dan efektif yang dilakukan didalam kelas. Namun karena adanya pandemi covid-19 menjadikan pembelajaran terhambat dan tidak terlaksana secara utuh. Sehingga hal yang terjadi sekarang justru banyak sekolah memindahkan proses belajar menjadi dari rumah atau dikenal dengan learn from home (LFH). Sehingga pembelajaran menjadi pasif dan kurang efektif dilakukan serta mempengaruhi motivasi juga hasil belajar dari peserta didik.

Berdasarkan observasi yang dilakukan kepada salah satu guru biologi melalui wawancara pada tanggal 12 Februari 2021, menyatakan bahwa setelah terjadinya wabah pandemi covid-19 kondisi motivasi dan hasil belajar siswa menurun. Dapat dilihat bahwa hanya $75 \%$ capaian belajar siswa yang mencapai KKM (kriteria ketuntasan minimal), dengan nilai KKM mata pelajaran biologi yaitu 70 . Hal tersebut diakibatkan karena kurang mampunya penggunaan media pembelajaran yang variatif, sehingga siswa merasa jenuh dan bosan dengan proses pembelajaran yang dilakukan. Oleh karena itu berdasarkan fakta di lapangan, selama masa pandemi covid-19 dibutuhkan media pembelajaran yang efektif baik bagi peserta didik agar pembelajaran tetap terlaksana secara aktif. Penggunaan media pembelajaran yang tepat akan mempengaruhi proses pembelajaran di rumah, sehingga dapat meningkatkan motivasi dan hasil belajar kognitif peserta didik. Hasil belajar siswa merupakan paradigma pembelajaran yang digunakan guru sebagai hasil prestasi siswa yang telah dilakukan selama proses pembelajaran (Nurawaliah, et al. 2021)

Dengan kondisi saat ini, pembelajaran yang tepat adalah dengan menggunakan sistem pembelajaran online atau daring (dalam jaringan) dengan pemanfaatan akses jaringan internet untuk menggunakan e-learning sebagai aplikasi penunjang pembelajaran. Bentuk e-learning yang nyaman digunakan dan familiar bagi siswa adalah dengan aplikasi whatsapp dan google classroom. Hal ini dikarenakan kedua aplikasi tersebut dapat diakses dengan mudah dan tidak ada biaya berlangganan aplikasi yang akan dikeluarkan. Selain itu, aplikasi whatsapp ini sangat familiar bagi semua kalangan, sehingga akan lebih mudah dlam pengoperasiannya dan efeknya juga sangat baik. Aplikasi google classroom memiliki tampilan yang sangat mudah dipahami dan sangat sederhana, sehingga siswa akan lebih mudah memahami materi pembelajaran yang diberikan oleh guru. 


\section{METODE PENELITIAN}

Dalam penelitian ini pendekatan yang digunakan adalah pendekatan kuantitatif dan metode quasi experimental (eksperimen semu) dengan rancangan penelitian one group pretest posttest design. Pada desain penelitian ini sebelum perlakuan dilakukan tes pendahuluan (pre test) untuk mengetahui pengetahuan awal siswa. Kemudian dilakukan tes akhir (post test) setelah perlakuan. Populasi dalam penelitian ini adalah siswa kelas XI IPA SMA Negeri 1 Sukadana yang berjumlah 41 orang dalam 2 kelas. Sampel yang digunakan dalam penelitian ini adalah kelas XI IPA 1 yang berjumlah 21 orang sesuai dengan kebutuhan penelitian dan pertimbangan, ditentukan dengan metode purposive sampling. Instrumen yang digunakan dalam penelitian ini adalah berupa angket dan soal. Instrumen soal berupa pilihan ganda yang berjumlah 20 item soal denga 4 pilihan jawaban, dan instrument angket yang berjumlah 12 butir pernyataan dengan 4 pilihan alternatif jawaban. Instrumen yang digunakan sebelumnya dilakukan expert judgement oleh 3 tim ahli, kemudian di uji cobakan kepada siswa yang selanjutnya dilakukan uji validitas dan reliabilitas. Analisis data yang dilakukan dalam penelitian ini pada instrumen soal dengan menggunakan uji normalitas, selanjutnya karena data penelitian berdistribusi normal dilakukan uji hipotesis dengan uji pengaruh yaitu uji $z$. Pada instrument angket analisis data dilakukan dengan menggunakan uji median, kemudian pengujian hipotesis dengan uji wiloxcon.

\section{HASIL DAN PEMBAHASAN}

Hasil penelitian yang telah dilakukan pada kelas XI IPA 1 SMA Negeri 1 Sukadana Ciamis dengan menggunakan aplikasi whatsapp group dan google classroom terhadap motivasi dan hasil belajar kognitif siswa pada materi sistem saraf diperoleh data sebagai berikut:

\section{Motivasi Belajar}

Tabel 1. Hasil Rata-rata Pretest, Post test dan N-Gain Instrumen Non Tes

\begin{tabular}{clcccc}
\hline \multirow{2}{*}{ No } & Statistik & \multicolumn{4}{c}{ Nilai } \\
\cline { 3 - 6 } & $\begin{array}{c}\text { Sebelum (pre } \\
\text { test) }\end{array}$ & $\begin{array}{c}\text { Sesudah (post } \\
\text { test) }\end{array}$ & N-Gain & Uji Angket \\
\hline 1 & Skor minimum & 17 & 29 & 39 & $0 \%$ \\
\hline 2 & Skor maksimum & 46 & 48 & 100 & $80,9 \%$ \\
\hline 3 & Rata- rata & 29,81 & 39,09 & 54 & $44,21 \%$ \\
\hline
\end{tabular}

Berdasarkan tabel 1, menunjukkan bahwa hasil rata-rata skor pre test yaitu dengan hasil 29,81 . Sedangkan rata-rata skor post test yaitu dengan hasil 39,09 , hasil rata-rata N-Gain yaitu 54 dan rata-rata uji angket sebesar $44,21 \%$.

Tabel 2. Hasil Uji Wilcoxon

\begin{tabular}{lll}
\hline Data & Hasil & Keterangan \\
\hline Me & 54 & $\begin{array}{l}\text { Whitung }>\text { Wdaftar maka penggunaan aplikasi Whatsapp } \\
\text { Group dan google classroom tidak berpengaruh terhadap } \\
\text { motivasi belajar siswa }\end{array}$ \\
\hline$W_{\text {dattung }}$ & 92 & motar
\end{tabular}

Hasil perhitungan berdasarkan tabel 2 dapat dijelaskan bahwa hasil uji median mengenai perhitungan penggunaan aplikasi whatsapp dan google classroom terhadap motivasi belajar siswa diperoleh hasil median sebesar 54 sedangkan $W_{\text {hitung }}$ dengan hasil 92 dan $W_{\text {daftar }} 59,11$ dengan taraf signifikansi 0,05. Hal ini menunjukkan bahwa $W_{\text {hitung }}$ lebih besar daripada $W_{\text {daftar }}$ atau $92>59,11$. 


\section{Hasil belajar kognitif}

Tabel 3. Hasil Rata-rata Pretest, Post test dan N-Gain Instrumen Tes

\begin{tabular}{clccc}
\hline \multirow{2}{*}{ No } & Statistik & \multicolumn{3}{c}{ Nilai } \\
\cline { 3 - 5 } & Skor minimum & 5 & $\begin{array}{c}\text { Sesudah (post } \\
\text { test) }\end{array}$ & N-Gain \\
\hline 1 & Skelum (pre test) & 65 & 63 \\
\hline 2 & Skor maksimum & 50 & 95 & 90 \\
\hline 3 & Rata-rata & 20,47 & 79,76 & 75 \\
\hline
\end{tabular}

Berdasarkan hasil pada Tabel 3, dapat di lihat bahwa secara keseluruhan terdapat peningkatan hasil belajar pada ranah kognitif siswa dengan kategori tinggi dengan nilai rata-rata $\mathrm{N}$ gain 75 .

Tabel 4. Uji Normalitas

\begin{tabular}{llll}
\hline Data & Hasil & Keterangan & \\
\cline { 1 - 2 } Chi kuadrat $\left(x^{2}\right)$ hitung & 0,57 & $\begin{array}{ll}x^{2} \text { hitung } \leq x^{2} \text { tabel maka data yang } \\
\text { digunakan berdistribusi normal. }\end{array}$ \\
\hline Chi kuadrat $\left(x^{2}\right)$ table & 5,99 & digun & \\
\hline
\end{tabular}

Berdasarkan tabel 4 diketahui bahwa $x^{2}$ hitung 0,57 dan $x^{2}$ tabel 5,99, data tersebut berdistribusi normal karena $x^{2}$ hitung $\leq x^{2}$ tabel atau 0,57 $\leq 5,99$. Selanjutnya data dianalisis dengan menggunakan perhitungan uji $Z$ agar dapat diketahui apakah hipotesis diterima atau ditolak. Hasil perhitungan uji $z$ dapat dilihat pada tabel 5 .

Tabel 5. Hasil Perhitungan Uji Z

\begin{tabular}{lcl}
\hline Data & Hasil & Keterangan \\
\hline$Z$ hitung & 1 & $\begin{array}{l}\text { Zhitung } \leq \text { Zdaftar maka maka penggunaan aplikas Whatsapp Group } \\
\text { dan google classroom tidak terdapat pengaruh terhadap hasil } \\
\text { belajar kognitif siswa }\end{array}$ \\
\hline Z table & 2,33 & \\
\hline
\end{tabular}

Tabel 5 menunjukkan $Z_{\text {hitung }}$ sebesar 1 dan $Z_{\text {tabel }}$ sebesar 2,33, karena $Z_{\text {hitung }} \leq Z_{\text {daftar }}$ maka hipotesis ditolak. Dengan demikian penggunaan aplikasi whatsapp group dan google classroom berpengaruh signifikan terhadap peningkatan hasil belajar siswa. Berdasarkan hasil analisis yang telah dilakukan maka diperoleh data sebagai berikut:

Diketahui bahwa berdasarkan hasil penelitian dan analisis data yang telah dilakukan, diperoleh data dengan rata-rata pretes 29,81, posttes 39,09 dan n-gain 54. Kemudian berdasarkan hasil analisis statistik dengan uji wilcoxon diperoleh nilai $W_{\text {hitung }}>W_{\text {daftar }}$ atau $92>59,11$ berada pada penolakan hipotesis, artinya berdasarkan data tersebut menunjukkan bahwa penggunaan media pembelajaran online whatsapp group dan google classroom pada mata pelajaran biologi tidak berpengaruh terhadap peningkatan motivasi belajar siswa kelas XI IPA 1 SMA Negeri 1 Sukadana pada materi sistem saraf. Selanjutntya berdasarkan uji angket yang dilakukan pada saat pelaksanaan kegiatan pembelajaran menggunakan aplikasi whatsapp dan google classroom yang bertujuan untuk meningkatkan motivasi belajar siswa pada mata pelajaran biologi. Diperoleh hasil uji angket dengan nilai rata-rata sebesar $44,21 \%$ hasil tersebut berada pada kategori rendah.

$\mathrm{Hal}$ ini tidak sejalan dengan penelitian yang dilakukan oleh Baser \& Rizal (2021) menyatakan bahwa penggunaan google classroom sebagai media pembelajaran sangat efektif dalam meningkatkan motivasi belajar siswa di masa pandemi seperti sekarang ini. Selanjutnya dalam penelitian yang dilakukan oleh Zahroh (2021) menyatakan bahwa penggunaan whatsapp sebagai media pembelajaran terbukti meningkatkan motivasi belajar pada siswa. Namun pada kenyataan di lapangan (SMA Negeri 1 Sukadana), pembelajaran yang menggunakan kolaborasi media pembelajaran belum terbiasa dilakukan, kebiasaan hanya menggunkan satu media dalam 
proses pembelajaran memberikan pengaruh yang sangat besar terhadap siswa. Pada saat pembelajaran siswa hanya mendapatkan materi yang disampaikan guru tanpa adanya pemanfaatan media lain untuk meningkatkan motivasi belajar siswa.

Dari penemuan penelitian tersebut, sejalan dengan beberapa faktor ketidak berpengaruhan, diantaranya dalam pembelajaran di masa pandemi seperti sekarang ini siswa memerlukan banyak dorongan agar tetap semangat dalam belajar, banyak siswa merasa bosan karena proses pembelajaran yang monoton, serta beberapa faktor lainnya seperti tidak memiliki telepon genggam yang memadai untuk menunjang proses pembelajaran, tidak memiliki akses internet yang lancar karena berada didaerah yang cenderung sulit signal. Selain itu juga ada sebagian siswa yang memilih untuk bekerja untuk membantu keuangan keluarga karena kondisi sedang sulit. Hal itu cenderung membuat siswa menjadi tidak memiliki semangat dan motivasi dalam belajar. Selain itu juga, hal tersebut disebabkan karena pernyataan dalam angket tidak sesuai dengan kondisi yang seharusnya.

Selanjutnya dari hasil penelitian diperoleh data dengan rata-rata nilai pretest sebesar 20,47, posttest sebesar 79,76 dan $\mathrm{N}$-gain sebesar 75 . Selanjutnya berdasarkan hasil analisis data penelitian tentang pengaruh penggunaan aplikasi whatsapp group dan google classroom pada mata pelajaran biologi pada materi sistem saraf terhadap hasil belajar kognitif siswa diperoleh nilai Zhitung $\leq$ Zdaftar atau $1 \leq 2,33$ berada pada penolakan hipotesis. Artinya tidak terdapat pengaruh yang signifikan dari penggunaan aplikasi whatsapp group dan google classroom dalam pembelajaran biologi pada materi sistem saraf di kelas XI IPA 1 SMA Negeri 1 Sukadana. Dari penemuan penelitian tersebut, sejalan dengan faktor ketidak berpengaruhan dari penggunaan kedua aplikasi tersebut, diantaranya adalah kurang anutusiasnya siswa dalam proses pembelajaran yang disebabkan karena waktu pembelajaran yang bertepatan dengan kegiatan pesantren ramadhan, sehingga siswa merasa terbebani dan menjadi kurang fokus dalam mengikuti proses pembelajaran. Faktor selanjutnya materi yang diberikan cenderung sulit, sehingga siswa menjadi lebih lambat dalam proses memahami materi tersebut dan siswa merasa proses pembelajaran menjadi membosankan dan kurang menarik karena materi yang diberikan cenderung sulit. Selain itu juga, materi tersebut cenderung kurang cocok apabila diberikan dengan menggunakan aplikasi whatsapp dan google classroom pada proses pembelajaran. Hal tersebut dikarenakan dalam penggunaan kedua aplikasi tersebut tidak dapat dilakukan dengan caravirtual (tatap muka), sehingga materi yang diberikan kurang tersampaikan kepada siswa dan menjadikan miss konsepsi pada siswa serta sulit dalam memahami materi yang telah diberikan

Hal ini tidak sejalan dengan penelitian Jannah \& Nurdianti (2021) menemukan bahwa penggunaan media pembelajaran online dapat berpengaruh terhadap peningkatan hasil belajar kognitif siswa dan dapat membantu siswa dalam kesulitan belajar serta memudahkan siswa dalam memahami materi pelajaran karena siswa dapat dengan mudah mengakses kembali materi yang dibagikan di media yang digunakan. Selanjutnya penelitian yang dilakukan oleh Permata \& Bhakti (2020) menyatakan bahwa penggunaan media pembelajaran online google classroom sangat efektif digunakan dalam proses pembelajaran, karena pada kenyataannya siswa masih membutuhkan guru secara langsung dalam proses pembelajaran.

\section{SIMPULAN}

Penggunaan whatsapp group dan google classroom tidak berpengaruh terhadap peningkatan motivasi belajar siswa pada mata pelajaran biologi. Hal ini disebabkan siswa berbagai faktor baik itu faktor internal (dari dalam diri siswa) maupun faktor eksternal (dari luar diri siswa).

Penggunaan aplikasi whatsapp group dan google classroom tidak berpengaruh terhadap peningkatan hasil belajar kognitif siswa pada mata pelajaran biologi khususnya materi sistem saraf. Hal ini disebabkan oleh berbagai faktor, diantanya faktor tersebut dapat berupa faktor yang ada dalam diri siswa seperti rasa malas, kurang antusias maupun dari lingkungannya yang kurang 
mendukung kelangsungan proses pembelajaran, karakteristik materi yang digunakan dalam pembelajaran yang cenderung sulit, sehingga hasilnya tidak sesuai dengan yang diharapkan.

\section{UCAPAN TERIMAKASIH}

Kepala Sekolah SMA Negeri 1 Sukadana Ciamis yang telah memberikan kesempatan dan izin untuk melakukan penelitian ini.

\section{DAFTAR PUSTAKA}

Amalia, T. (2019).Penggunaan Media Google Form Dalam Evaluasi Pembelajaran Bahasa Arab Maharah Kitabah.Prosiding Konferensi Nasional Bahasa Arab V, 5, 318-323.

Baser, A., \& Rizal, F. (2021). Dampak Positif Penggunaan Google Classroom Terhadap Motivasi Belajar dan Hasil Belajar Siswa pada Mata Pelajaran TIK di Masa Pandemi Covid-19. 5(1), 154-162.

Emda, A. (2017). Kedudukan Motivasi Belajar Siswa Dalam Pembelajaran. J. Lantanida. 5(2): $172-$ 196.

Jannah, M., \& Nurdianti, N. (2021). Pengaruh Pembelajaran Online Berbantuan Google Classroom terhadap Hasil Belajar Siswa. JRIP: Jurnal Riset dan Inovasi Pembelajaran 1(1), 75-84.

Nurawaliah, N., Rusyana, A \& Sopyan, T. (2021). Pengaruh model discovery learning berbasis concept mapping terhadap hasil belajar kognitif. J-KIP (Jurnal Keguruan dan IImu Pendidikan), 2 (2), 33-38.

Permata, A., \& Bhakti, Y. B. (2020). Keefektifan Virtual Class dengan Google Classroom dalam Pembelajaran Fisika Dimasa Pandemi Covid-19. JIPFRI (Jurnal Inovasi Pendidikan Fisika Dan Riset IImiah), 4(1), 27-33. https://doi.org/10.30599/jipfri.v4i1.669

Zahroh, F. (2021). Pengaruh Penggunaan Media Sosial Whatsapp Terhadap Motivasi Belajar Siswa Kelas Iv Sdn Pakong 1 Pamekasan Di Masa Pandemi Covid-19. Edukasi Tematik: Jurnal Pendidikan Guru Sekolah Dasar. 2(1), 12-21. 